\title{
Transcriptional regulation of the COX-2 expression by nitric oxide in colon cancer cell lines
}

\author{
QIANG LIU $^{1}$, HIROYASU INOUE ${ }^{2}$ and RATHA MAHENDRAN ${ }^{1}$ \\ ${ }^{1}$ Department of Surgery, Yong Loo Lin School of Medicine, National University of Singapore, Singapore 119260, \\ Repulic of Singapore; ${ }^{2}$ Department of Food Science and Nutrition, Nara Women's University, Nara, Japan
}

Received July 4, 2007; Accepted August 22, 2007

\begin{abstract}
To determine the effect of nitric oxide (NO) on the cyclooxygenase-2 (COX-2) regulation in colon cancer cell lines we used the physiological NO donor GSNO. The proximal $6.6 \mathrm{~kb}$ of the COX-2 promoter was cloned into the pGL3 basic vector and the sequential deletion of the $6.6 \mathrm{~kb}$ COX-2 promoter generated promoter constructs of $4,2.6,1.9$ and $0.9 \mathrm{~kb}$. These constructs clearly show that the main regulatory region lies within $0.9 \mathrm{~kb}$ of the transcription start site. Therefore, constructs of the main transcription binding sites within this region namely CRE, NF-IL6 and NF- $\mathrm{KB}$ and mutations of these sites were used to monitor the transcriptional activation of COX-2. This study was performed on the colon cancer cell lines HCA7 and HCT116 which have a differential expression of COX-2. There was no evidence that the luciferase activity is negatively affected by $\mathrm{NO}$ as was previously reported. The CRE and NF-IL6 binding sites within this region were responsible for the constitutive and physiological NO-induced COX-2 transcriptional activity in the HCA7 and HCT116 cells. While NF-кB involvement was only observed in the HCT116 cells, the cell lines displayed increased NF-KB transcriptional activity after exposure to NO.
\end{abstract}

\section{Introduction}

Cyclooxygenase (COX) catalyzes the rate-limiting step in the synthesis of prostaglandins (PGs). There are two COX isozymes: COX-1 and COX-2. COX-1 is constitutively expressed in most tissues and cells under normal physiological conditions and is responsible for the maintenance of the integrity of the gastric mucosa, regulation of renal blood flow

Correspondence to: Dr Ratha Mahendran, Department of Surgery, National University of Singapore, 5 Lower Kent Ridge Road, Singapore 119074, Republic of Singapore

E-mail: surrm@nus.edu.sg

Key words: nitric oxide, cyclooxygenase-2, CRE and NF-IL6 transcription factor binding sites and platelet aggregation. In contrast, $\mathrm{COX}-2$ is undetectable in normal tissues but can be rapidly and transiently induced by cytokines, oncogenes and growth factors.

Constitutive COX-2 expression and activity is found in colon adenomas/polyps and colon cancer tissues $(1,2)$. This expression can be regulated at the transcriptional level $(3,4)$. Most studies have focused on the cis-acting elements within 250 bases of the transcriptional start site which include the cyclic-AMP response element binding protein (CREB), the nuclear factor $\mathrm{\kappa B}(\mathrm{NF}-\mathrm{\kappa B})$ and the CCAAT-enhancer binding protein (C/EBP), PEA3 and NFAT (Nuclear factor activating $\mathrm{T}$ cells) binding sites (5-7). However, a peroxisome proliferator-activated receptor (PPAR) site at $-3900 \mathrm{bp}$ can regulate enhanced COX-2 production by fatty acids and prostaglandins and the TBE site at -1007 up-regulates COX-2 expression when bound by a TCF4 and $\beta$-catenin complex $(8,9)$.

The inducible nitric oxide synthase (iNOS) protein can correlate with the COX-2 expression in colon cancer (10). Cell line studies also confirmed that nitric oxide (NO) up-regulates the COX-2 protein and activity $(11,12)$. The effect of $\mathrm{NO}$ on a COX-2 transcription have been studied using several NO donors namely SNAP, SIN-1, NOR-1, SNP, Deta/NO and NOR4 (13-15) and the results obtained were as varied as the cell lines studied. These NO donors have different effects on vasodilation and platelet aggregation which are common activities of NO (16). Some of these NO donors namely SIN-1, SNP and SNAP are also peroxynitrite generators $(17,18)$ while Deta/NO induces oxidative stress (19). Therefore, to determine the effect of $\mathrm{NO}$ on COX-2 regulation we used S-nitrosothiol, GSNO, which is a physiological NO donor and a potential storage and transport vehicle for $\mathrm{NO}$ in the body.

We previously showed that GSNO treatment up-regulates PGE2 production and COX-2 in colon cancer cell lines (20). The proximal $6.6 \mathrm{~kb}$ of the COX-2 promoter was cloned into the pGL3 basic vector and the sequential deletion of the $6.6 \mathrm{~kb}$ COX-2 promoter generated promoter constructs of $4,2.6,1.9$ and $0.9 \mathrm{~kb}$. These constructs together with those of the $-250 \mathrm{bp}$ region generated by Inoue et al (5) were used to monitor the transcriptional activation of COX-2 by NO generated from GSNO. This study was performed on the colon cancer cell lines HCA7 and HCT116 which have a differential expression of COX-2. 
Table I. The quantity of each plasmid used for transfection.

\begin{tabular}{lccc}
\hline Promoter construct & Plasmid size & \multicolumn{2}{c}{ DNA $(0.392 \mu \mathrm{g})+0.008 \mu \mathrm{g}$ pRL-TK } \\
\cline { 3 - 4 } Insert size $(\mathrm{kb})$ & $(\mathrm{kb})$ & Promoter $(\mu \mathrm{g})$ & pGL3 basic $(\mu \mathrm{g})$ \\
\hline 6.6 & 11.4 & 0.392 & - \\
4 & 8.8 & 0.303 & 0.089 \\
2.6 & 7.4 & 0.254 & 0.138 \\
1.9 & 6.7 & 0.23 & 0.162 \\
0.9 & 5.7 & 0.196 & 0.196 \\
TATA box & 5 & 0.172 & 0.22 \\
pGL3 basic & 4.8 & - & 0.392
\end{tabular}

\section{Materials and methods}

Cell culture. The human colonic adenocarcinoma cell lines, HCA7 (a gift from Susan C. Kirkland, The Royal Postgraduate Medical School, City, UK) and HCT116 (from the American Type Culture Collection, MD, USA) were used. All cell lines were grown at $37^{\circ} \mathrm{C}$ in a humidified atmosphere of $5 \% \mathrm{CO}_{2}$ in McCoy's 5A medium (Sigma Chemical Co., MO, USA) supplemented with $10 \%$ fetal bovine serum (Trace Scientific Ltd, Melbourne, Australia), penicillin (50 units $/ \mathrm{ml}$ ) and streptomycin (50 $\mu \mathrm{g} / \mathrm{ml}$; Sigma Chemical Co.). Cells were routinely sub-cultured using trypsin $(0.5 \%$ trypsin/ $0.2 \%$ EDTA, Sigma Chemical Co.).

Chemicals. S-Nitrosoglutathione (GSNO, Sigma Chemical Co.) was freshly dissolved in PBS immediately before adding it into the medium.

Isolation of the $6.6 \mathrm{~kb}$ COX-2 promoter. Genomic DNA was extracted from the FHs 74 Int human small intestinal normal cells (ATCC). The proximal $6.6 \mathrm{~kb}$ COX-2 promoter was amplified using the Expand long template PCR system (Roche Diagnostics, Mannheim, Germany) and the following primers: Primer -6481: 5'-CGTAACGCGTGGTGTGTCTTATGGTG CAGAATGCGG-3' and Primer +100: 5'-CGTACTCGAGC TTTGCTGTCTGAGGGCGTCTGG-3' containing an MluI and XhoI site, respectively (underlined), to facilitate cloning into the pGL3 basic vector [containing Photinus pyralis (firefly) luciferase, Promega, WI, USA]. The -49 bp fragment of the promoter minus all cis elements but containing the TATA box was constructed by using the following primer: Primer -49: 5'-CATA ACGCGTGGGCTTGGTTTTCAG TCT-3' together with the Primer +100 and Taq DNA polymerase (Promega) and cloned as described above. The plasmids were sequenced to confirm their identity.

Reporter constructs. After restricting enzyme digestion of the $6.6 \mathrm{~kb}$ COX-2 pGL3 plasmid with SacI; ScaI and HindIII; HincII and HindIII; StuI and HindIII, the isolated fragments were self-ligated or ligated with pGL3 which was digested with SmaI and HindIII to produce the 0.9, 1.9, 2.6 and $4 \mathrm{~kb}$ promoter constructs. The six COX-2 promoter constructs namely:-327/+59, CRM, ILM, KBM, CRM+ILM, -52/+59 were previously described (5). The pNF- $\kappa \mathrm{B}-\mathrm{luc}$ and its control vector were from Clonetech, CA, USA.

Transfection of colon cancer cells. Cells $\left(1 \times 10^{5}\right)$ were plated per well in 24-well culture plates. After $24 \mathrm{~h}$, the cells were transfected with the mixture of $0.4 \mu \mathrm{g}$ DNA $/ 4 \mu 1$ lipofectamine Plus $/ 3 \mu 1$ lipofectamine (Invitrogen, NY, USA) or $0.2 \mu \mathrm{g}$ DNA $/ 2 \mu 1$ lipofectamine Plus $/ 3 \mu 1$ lipofectamine for $3 \mathrm{~h}$. To normalize the transfection efficiency the pRL-TK plasmid [containing Renilla reniformis (sea pansy) luciferase] was included in the total DNA used for transfection. The ratio of the COX-2 promoter constructs to pRL-TK plasmid DNA was 50:1. Thirty hours after transfection, the cells were treated with GSNO $500 \mu \mathrm{M}$ or spent GSNO control for $15 \mathrm{~h}$. Then the cells were lysed and the cell extracts were assayed for the luciferase activities using the Dual-Luciferase Reporter Assay System (Promega). The spent control for GSNO treatment was produced by pre-incubation of the GSNO $(500 \mu \mathrm{M})$ in a blank medium at $37^{\circ} \mathrm{C}$ for $24 \mathrm{~h}$.

To compare the transfection activity between the plasmids, equal molar concentrations of the different plasmids (equivalent to $0.392 \mu \mathrm{g}$ of the $6.6 \mathrm{~kb}$ promoter construct) were used for transfection. To ensure that the total amount of DNA used for transfection was constant, the difference was made up with the pGL3 basic vector that had no significant luciferase activity (Table I). The total amount of DNA used in the transfection was $0.4 \mu \mathrm{g}(0.392 \mu \mathrm{g}$ plasmid DNA+0 $0.008 \mu \mathrm{g}$ pRL-TK $)$ and this was mixed with $4 \mu 1$ lipofectamine Plus and $3 \mu 1$ lipofectamine.

Statistical analysis. A one-way ANOVA, with a Bonferroni test was used to compare the relative luciferase activity and determine whether there was a significant difference. Statistical significance was set at $\mathrm{P}<0.05$.

\section{Results}

Optimal induction of the COX-2 promoter activity by the GSNO. HCA7 cells were co-transfected with the $6.6 \mathrm{~kb}$ insert and the pRL-TK plasmid and then treated with GSNO $500 \mu \mathrm{M}$ for different lengths of time. This dose was chosen as in a previous study there was maximal stimulation of the PGE2 production at this dose (20). Fig. 1 shows that the COX-2 
Table II. The effect of GSNO on firefly (F) and Renilla (R) luciferase activity.

\begin{tabular}{llcccc}
\hline Plasmid & & $6.6 \mathrm{~kb}$ insert & pGL3 basic & $-327 /+59$ & $-52 /+59$ \\
\hline Spent & RLU $(\mathrm{F}) / \mu \mathrm{g}$ & $12295 \pm 838$ & $124 \pm 9$ & $6076 \pm 163$ & $211 \pm 23$ \\
GSNO & RLU $(\mathrm{R}) / \mu \mathrm{g}$ & $5117 \pm 315$ & $4072 \pm 106$ & $5597 \pm 208$ & $5591 \pm 250$ \\
& Ratio & $2.40 \pm 0.07$ & $0.03 \pm 0.002$ & $1.09 \pm 0.06$ & $0.04 \pm 0.003$ \\
$\mathrm{GSNO}$ & RLU $(\mathrm{F}) / \mu \mathrm{g}$ & $20828 \pm 731^{\mathrm{a}}$ & $159 \pm 19$ & $8959 \pm 567^{\mathrm{a}}$ & $304 \pm 65$ \\
$500 \mu \mathrm{M}$ & RLU $(\mathrm{R}) / \mu \mathrm{g}$ & $5872 \pm 349$ & $4145 \pm 357$ & $5723 \pm 170$ & $5917 \pm 227$ \\
& Ratio & $3.56 \pm 0.12$ & $0.04 \pm 0.006$ & $1.57 \pm 0.08$ & $0.05 \pm 0.009$ \\
\hline
\end{tabular}

${ }^{a} \mathrm{P}<0.05$ when the GSNO-treated group was compared with its spent GSNO control.

promoter activity measured as relative light units (RLU) increased with the time of exposure to GSNO, reaching a maximum at $15 \mathrm{~h}$ before declining. This reduction correlates with the depletion of GSNO in solution which occurs within $10 \mathrm{~h}$ in media in the presence of serum (21). Therefore, for all subsequent work the cells were exposed to the GSNO for $15 \mathrm{~h}$ and control cells were treated with the spent GSNO. GSNO breaks down to produce GSH and nitrates and nitrite. Therefore, the spent control confirms that the effects observed are due to NO and not its breakdown products.

GSNO did not have an inhibitory effect on the firefly and renilla luciferase activity. Fan et al (15) reported that three NO donors: sodium nitroprusside (SNP), Deta/NO and NOR4, inhibited the firefly luciferase activity in a dose-dependent manner by decreasing luciferase mRNA stability. To determine if the GSNO would also have this effect, the activity of the firefly and renilla luciferase were monitored after GSNO treatment. HCA7 cells were transfected with the following plasmids: $6.6 \mathrm{~kb}$ insert, pGL3 basic, $-327 /+59$ and $-52 /+59$ and then treated with GSNO. Spent GSNO $(500 \mu \mathrm{M})$ was used as a control. After normalization with the protein content, there was no significant difference in the RLU produced by renilla luciferase per $\mu \mathrm{g}$ protein between the control and GSNO-treated HCA7 cells transfected with the $6.6 \mathrm{~kb}$, pGL3 basic, $-327 /+59$ and $-52 /+59$ plasmids (Table II). However, GSNO treatment significantly increased the RLU produced by the firefly luciferase per $\mu \mathrm{g}$ protein in HCA7 cells which were transfected with the $6.6 \mathrm{~kb}$ and $-327 /+59$ promoter plasmids but not those transfected with the pGL3 basic and $-52 /+59$ control plasmids. This indicates that NO did not have an inhibitory effect on the firefly luciferase.

Induction of the COX-2 promoter activity by NO. The GSNO significantly increased the transcriptional activity of the 6.6, 4, 2.6, 1.9 and $0.9 \mathrm{~kb}$ COX-2 promoter plasmids (1.5-fold increase over unstimulated cells). However, there was no significant difference among these plasmids in the control and GSNO-treated groups. The transcriptional activity in the TATA box insert was $<90 \%$ and the GSNO did not stimulate it. This suggested that the $0.9 \mathrm{~kb}$ proximal promoter sequence

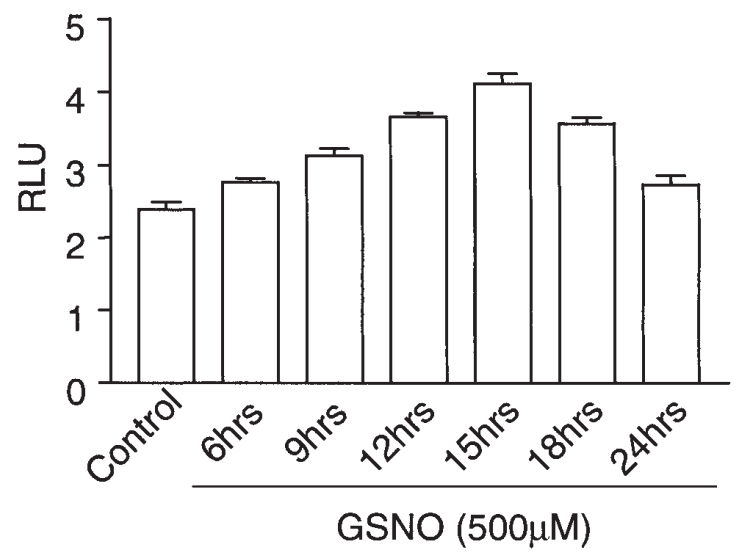

Figure 1. Optimization of the duration of the GSNO treatment required to induce increased COX-2 promoter activity is shown. HCA7 cells were plated at $1 \times 10^{5}$ cells per well in 24 -well plates $24 \mathrm{~h}$ prior to transfection. The cells were co-transfected with $0.196 \mu \mathrm{g}, 6.6 \mathrm{~kb}$ insert plasmid and $0.004 \mu \mathrm{g}$ pRL-TK plasmid (ratio 49:1, total $0.2 \mu \mathrm{g}$ DNA) using $3 \mu 1$ lipofectamine and $2 \mu \mathrm{l}$ Plus reagent. After being treated with GSNO $500 \mu \mathrm{M}$ for different lengths of time, the cells were lysed at $48 \mathrm{~h}$ after transfection. The relative luciferase activities were determined using the Dual-luciferase reporter assay system. The experiments were done in triplicate $(n=3)$ and repeated twice.

is critical for COX-2 transcription in the control and GSNOtreated cells. The activity of the pGL3 basic vector was only $20 \%$ of the TATA box insert (Fig. 2).

The proximal 327 bp of the COX-2 promoter constructs. We examined the activity of the proximal 327 bp of the COX-2 promoter and found it to be similar to the $0.9 \mathrm{~kb}$ promoter plasmid. This region contains binding sites for several transcription factors including NF- $\mathrm{B}$, NF-IL6 and CREB. Six plasmids containing wild-type or mutations in the binding sites for these 3 transcription factors were transfected into HCA7 and HCT116 to analyze the transcriptional activity of the proximal part of the COX-2 promoter and its regulation by NO. The design and transcriptional activity of the six plasmids were shown in Fig. 3 (A-C). Mutation of the CRE (CRM) or NF-IL6 binding site (ILM) decreased the constitutive transcriptional 

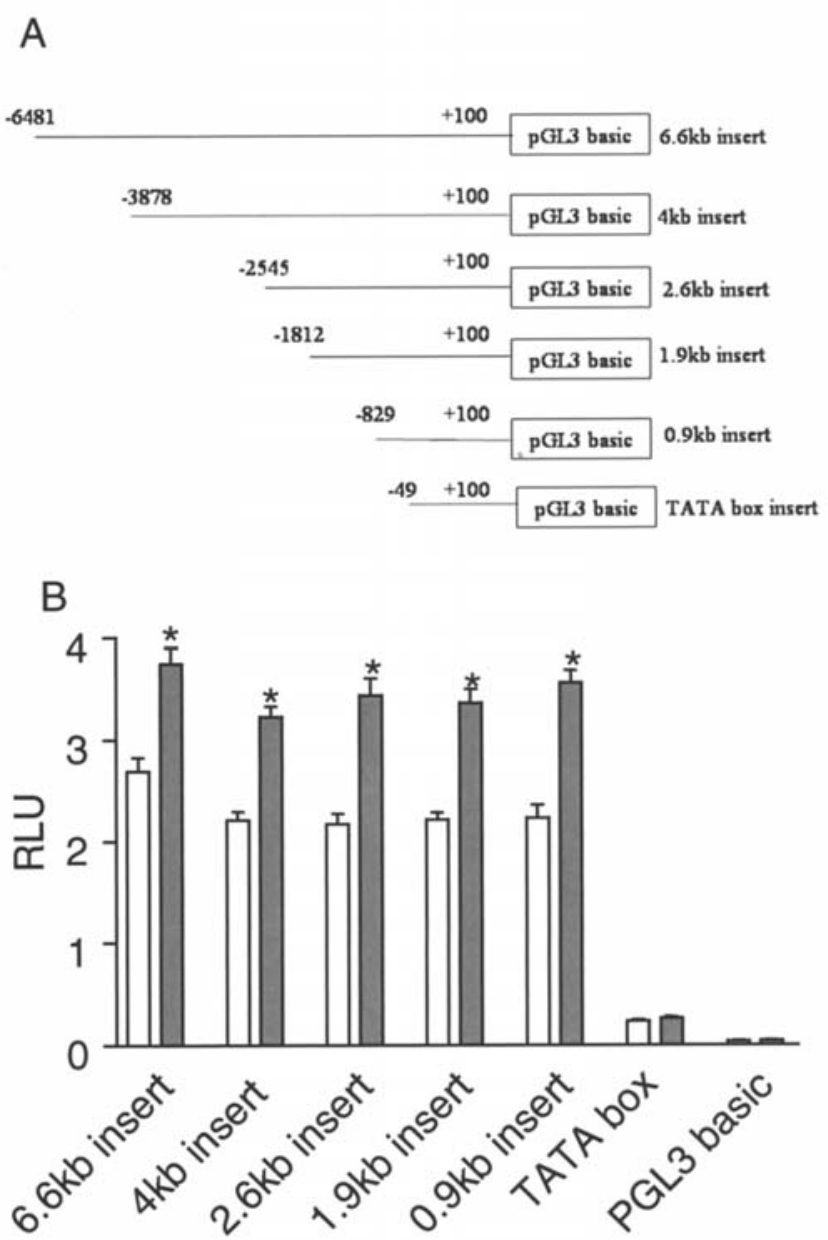

Figure 2. The effect of the GSNO on the COX-2 promoter activity using a $6.6 \mathrm{~kb}$ COX-2 promoter cloned in pGL3 and the sequential deletions of this promoter is shown. (A) A schematic representation of the reporter plasmids produced. (B) HCA7 cells were plated in 24-well plates. The transient transfection was carried out $24 \mathrm{~h}$ later. After $33 \mathrm{~h}$, the cells were treated with GSNO $500 \mu \mathrm{M}$ for $15 \mathrm{~h}$. The clear bars represent the luciferase activity in the control cells treated with spent GSNO and the shaded bars the luciferase activity in the GSNO-treated cells. The experiments were done in triplicate and repeated twice $(n=6) .{ }^{*} \mathrm{P}<0.05$ compares the relative luciferase activity of GSNO-treated cells to that of control cells transfected with the same plasmid.

activity of COX-2 in HCA7 cells by $>80$ and $70 \%$, respectively (Fig. 3B). Mutation of the CRE and NF-IL6 binding sites (CRM+ILM) further decreased the transcriptional activity by $>90 \%$. However, the mutation of the NF- $\kappa \mathrm{B}$ binding site (KBM) had no significant effect on the transcriptional activity of the COX-2 promoter. The GSNO significantly increased the transcriptional activity in cells transfected with the $-327 /$ +59 or KBM plasmids, but failed to do so in the CRM, ILM, CRM+ILM transfected cells.

Although HCT116 has a low constitutional COX-2 activity (3), as shown in Fig. 3C, it had a similar pattern of transcriptional regulation as $\mathrm{HCA} 7$ except that the mutation of the $\mathrm{NF}-\kappa \mathrm{B}$ binding site (KBM) significantly decreased the transcriptional activity of COX-2. This decrease was much smaller than that observed with CRM and ILM. This suggests that the binding sites of CRE and NF-IL6 in the proximal human COX-2 promoter are critical for the transcriptional
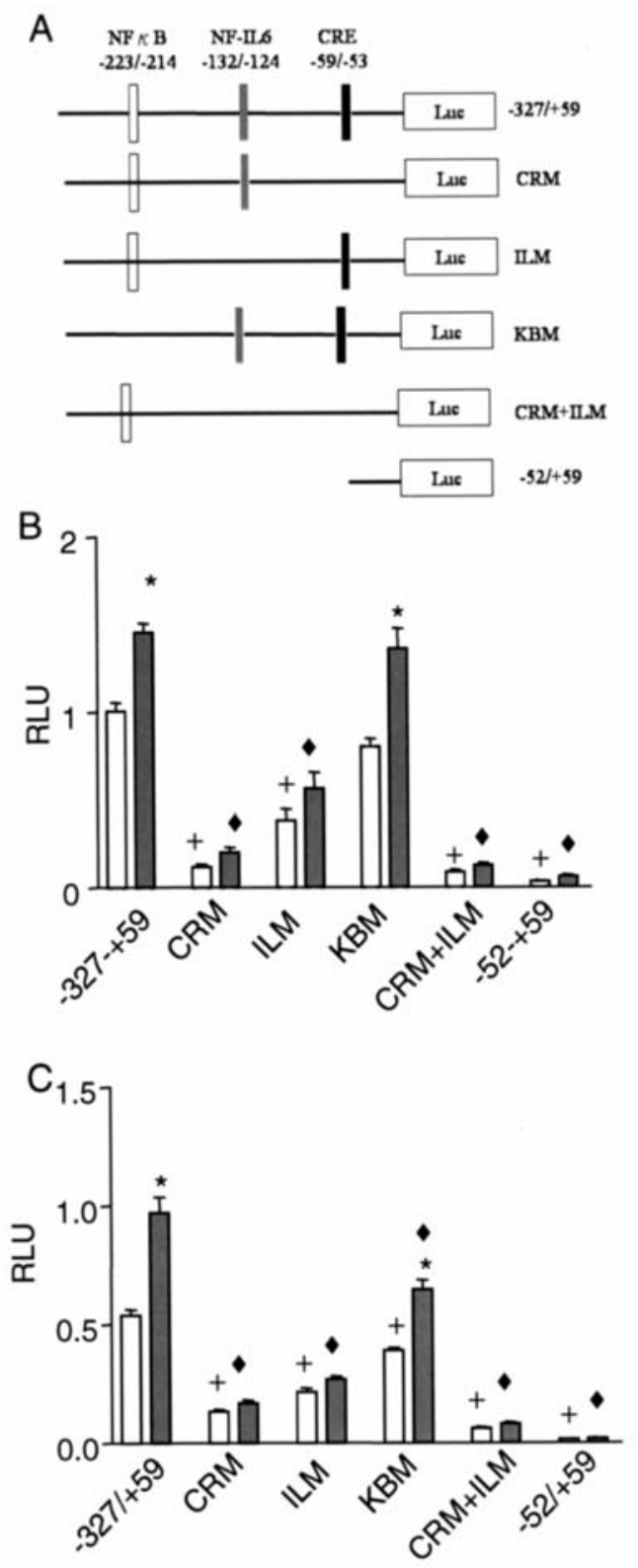

Figure 3 . The design and transcriptional activity of the reporter plasmids containing the region from -250 to the transcription start site of the human COX-2 gene with the known transcription factor binding sites mutated is shown. (A) A schematic representation of the design of the reporter plasmids. (B) HCA7 was plated at $10^{5}$ cells per well in a 24 -well plate. The transient transfection was done $24 \mathrm{~h}$ later. Thirty-three hours after the transfection, the GSNO group was treated with GSNO $500 \mu \mathrm{M}$ for $15 \mathrm{~h}$. The clear bars represent the luciferase activity in the control cells (treated with spent GSNO) and the shaded bars the luciferase activity in the GSNO-treated cells. (C) HCT116 cells were plated at $3 \times 10^{4}$ cells per well in a 24 -well plate. The transient transfection was done $24 \mathrm{~h}$ later. Thirty-three hours after the transfection, the GSNO group was treated with GSNO $500 \mu \mathrm{M}$ for $15 \mathrm{~h}$. The clear bars represent the luciferase activity in the control cells and the shaded bars the luciferase activity in the GSNO-treated cells. The experiments were done in triplicate and repeated twice $(n=6) .{ }^{*} \mathrm{P}<0.05$ when the GSNO-treated sample was compared with the spent GSNO-treated control of the same plasmid. ${ }^{+} \mathrm{P}<0.05$ when the plasmid in control was compared with the $327 /+59$ control. ${ }^{\star} \mathrm{P}<0.05$ when the GSNO-treated plasmid was compared with the GSNO-treated $-327 /+59$ plasmid.

activity of COX-2 in the control and GSNO-treated colon cancer cells but the NF- $\mathrm{\kappa B}$ can modulate this transcriptional activity. 

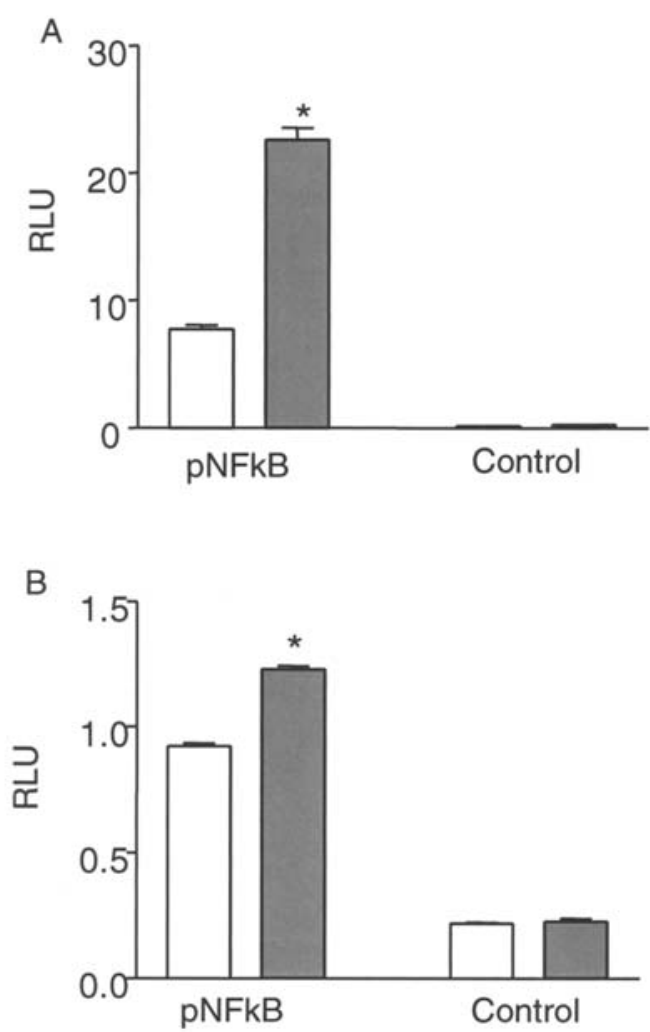

Figure 4. The NF-кB activity in HCA7 and HCT116 cells. (A) HCA7 and (B) HCT116 cells were plated at $10^{5}$ or $3 \times 10^{4}$ cells per well in 24 -well plates. The transient transfection was done $24 \mathrm{~h}$ later with the NF- $\mathrm{\kappa B}$ reporter plasmid $(\mathrm{NF}-\mathrm{KB})$ or a control vector (control). Thirty-three hours after the transfection, the GSNO group was treated with GSNO $500 \mu \mathrm{M}$ for $15 \mathrm{~h}$. The clear bars represent the luciferase activity in cells (spent GSNO-treated) and the shaded bars the luciferase activity in GSNO-treated cells. The experiments were done in triplicate and repeated twice $(n=6) .{ }^{*} \mathrm{P}<0.05$ when GSNO-treated was compared with its own spent GSNO-treated sample.

$N F-\kappa B$ activity. A plasmid with NF- $\kappa \mathrm{B}$ binding sites was transfected into the HCT116 and HCA7 cells to monitor the effect of the GSNO on the NF-кB activity. The GSNO treatment significantly increased the NF- $\mathrm{B}$ activity in HCA7 cells by almost 3 -fold and $30 \%$ in HCT116 (Fig. 4). Therefore, the lack of effect of the $\mathrm{NF}-\kappa \mathrm{B}$ mutation in the COX-2 promoter of HCA7 cells is not indicative of a lack of NF-кB function in these cell lines.

\section{Discussion}

The inhibitory effect of NO donors on the firefly luciferase activity previously reported by Fan et al (15) was not observed. This may be due to the fact that GSNO is a physiological NO donor. Its breakdown products include GSH and nitrate/nitrite and these may have fewer side effects than the breakdown products of other NO donors. The short exposure time to the GSNO in our experiment compared to the $20 \mathrm{~h}$ used by Fan et al (15) and the kinetics of the GSNO decomposition which occurs within $10 \mathrm{~h}$ in the media may be the reason why we did not observe a NO-induced decrease in luciferase activity (21).

By using GSNO, we found that there was no significant difference among the relative luciferase activities of the COX-2 promoter constructs from the 6.6 to $0.9 \mathrm{~kb}$ insert either in the presence of GSNO or spent GSNO. This suggested that the sequences between -6481 and -829 may not be critical for COX-2 transcriptional activation by NO. However, the deletion of the COX-2 promoter sequence between -829 to -49 significantly decreased promoter activity by $90 \%$ and completely abolished the response to NO.

NF-кB, NF-IL6/C/EBP, PEA3, NFAT and CRE (5-7) are transcription factors with binding sites within $-250 \mathrm{~kb}$ of the start site. Mutation of the CRE (CRM), the NF-IL6 binding site (ILM) or both sites, resulted in $\sim 80,70$ or $90 \%$ decrease, respectively, in the constitutive transcriptional activity of COX-2 in HCA7 cells. This is consistent with previous studies on the role of CRE and NF-IL6 sites on the transcriptional regulation of COX-2 in various cell types (22). NO failed to significantlystimulate the transcriptional activities of CRM, ILM and CRM+ILM, indicating that CRE and NF-IL6 are also critical for the transcriptional activation by NO. The spent GSNO data indicate that these are NO stimulated events.

The role of $\mathrm{NF}-\mathrm{\kappa B}$ in the regulation of $\mathrm{COX}-2$ is controversial. There are studies that suggest that $\mathrm{NF}-\kappa \mathrm{B}$ activation may play an important role in promoting COX-2 transcription in cancers associated with inflammation (23-26) and a study that indicates that $\mathrm{NF}-\kappa \mathrm{B}$ may not be involved in $\mathrm{COX}-2$ transcription (27). This could be due to the p53 status of the cell lines used as $\mathrm{NF}-\mathrm{\kappa B}$ activation has been linked to $\mathrm{p} 53$ expression (28). HCA7 has a mutant p53 and therefore increased basal and NO-activated NF- $\mathrm{BB}$ activity. However, mutation of the NF- $\kappa \mathrm{B}$ site does not affect the COX-2 expression. HCT116 which has a wild-type p53 has a lower $\mathrm{NF}-\kappa \mathrm{B}$ activity but the expression of COX-2 appears to be

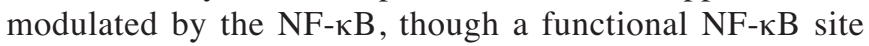
alone is not able to induce the COX-2 expression in HCT116 cells. These results are consistent with the ability of NO to induce a p53 nuclear accumulation at low doses such as that released by $0.5 \mu \mathrm{M}$ GSNO (29) and the ability of a wild-type p53 to modulate NF-кB regulation of the COX-2 (30).

In contrast to our results, Liu et al (14) working with murine and human colon cell lines found that the NO donors SIN-1, NOR-1 and SNAP induced the B-catenin expression and increased the PEA3 expression which resulted in a COX-2 activation via the ETS sites and NF-IL6 site. Park et al (13) found, using a head and neck squamous cell carcinoma cell line that SNAP induced soluble guanylate cyclase, p38 and c-Jun NH2-terminal kinase and this up-regulated CREB, ATF-2 and c-jun resulting in a COX-2 expression via the CRE but that the NF-IL6 mutation had no effect on the COX-2 expression. A study by Chen et al (31) working with gastric cell lines, indicated that reactive oxygen species activated COX-2 via the NF-IL6 and CRE sites by enhancing the binding of C/EBPS to these sites, as did studies by Inoue et al and Tamura et al $(32,33)$ in vascular endothelial and endometrial stromal cells. These studies indicate that the transcription factors involved in NO-mediated COX-2 expression vary with the cell lines and drugs used to generate NO.

Our data show that NO generated from GSNO induces the COX-2 expression via NF-IL6 and CRE in the HCA7 and HCT116 cells. These sites also regulate the basal COX-2 
expression in the colon cancer cell lines. The role of NF-кB in a NO-regulated COX-2 expression, however, appears to be dependent on the p53 status of the cell line.

\section{Acknowledgements}

This study was supported by a grant from the National Medical Research Council of Singapore (NMRC/0315/1998).

\section{References}

1. Eberhart CE, Coffey RJ, Radhika A, Giardiello FM, Ferrenbach S and DuBois RN: Up-regulation of the cyclooxygenase-2 gene expression in human colorectal adenomas and adenocarcinomas. Gastroenterology 107: 1183-1188, 1994.

2. Rigas B, Goldman IS and Levine L: Altered eicosanoid levels in human colon cancer. J Lab Clin Med 122: 518-523, 1993

3. Kutchera W, Jones DA, Matsunami N, et al: Prostaglandin H synthase-2 is expressed abnormally in human colon cancer: evidence for a transcriptional effect. Proc Natl Acad Sci USA 93: 4816-4820, 1996

4. Shao J, Sheng H, Inoue H, Morrow JD and DuBois RN: Regulation of constitutive cyclooxygenase-2 expression in colon carcinoma cells. J Biol Chem 275: 33951-33956, 2000.

5. Inoue H, Nanayama T, Hara S, Yokoyama $C$ and Tanabe T: The cyclic-AMP response element plays an essential role in the expression of the human prostaglandin-endoperoxide synthase-2 gene in differentiated U937 monocytic cells. FEBS Lett 350: 51-54, 1994.

6. Howe LR, Crawford HC, Subbaramaiah K, Hassell JA, Dannenberg AJ and Brown AM: PEA3 is up-regulated in response to Wnt1 and activates the expression of cyclooxygenase-2. J Biol Chem 276: 20108-20115, 2001.

7. Duque J, Fresno M and Iniguez MA: Expression and function of the nuclear factor of activated $\mathrm{T}$ cells in colon carcinoma cells: involvement in the regulation of cyclooxygenase-2. J Biol Chem 280: 8686-8693, 2005.

8. Meade EA, McIntyre TM, Zimmerman GA and Prescott SM: Peroxisome proliferators enhance cyclooxygenase-2 expression in epithelial cells. J Biol Chem 274: 8328-8334, 1999.

9. Araki Y, Okamura S, Hussain SP, et al: Regulation of cyclooxygenase-2 expression by the Wnt and ras pathways. Cancer Res 63: 728-734, 2003.

10. Bing RJ, Miyataka M, Rich KA, Hanson N, Wang X, Slosser HD and Shi SR: Nitric oxide, prostanoids, cyclooxygenase and angiogenesis in colon and breast cancer. Clin Cancer Res 7: 3385-3392, 2001

11. Mei JM, Hord NG, Winterstein DF, Donald SP and Phang JM: Expression of prostaglandin endoperoxide $\mathrm{H}$ synthase-2 induced by nitric oxide in conditionally immortalized murine colonic epithelial cells. FASEB J 14: 1188-1201, 2000.

12. Kim SF, Huri DA and Snyder SH: Inducible nitric oxide synthase binds, S-nitrosylates and activates cyclooxygenase-2. Science 310 : 1966-1970, 2005.

13. Park SW, Sung MW, Heo DS, Inoue H, Shim SH and Kim KH: Nitric oxide up-regulates the cyclooxygenase-2 expression through the cyclic-AMP response element in its promoter in several cancer cell lines. Oncogene 24: 6689-6698, 2005.

14. Liu Y, Borchert GL and Phang JM: Polyoma enhancer activator 3, an ets transcription factor, mediates the induction of cyclooxygenase- 2 by nitric oxide in colorectal cancer cells. J Biol Chem 279: 18694-18700, 2004.

15. Fan X, Roy E, Zhu L, Murphy TC, Kozlowski M, Nanes MS and Rubin J: Nitric oxide donors inhibit luciferase expression in a promoter-independent fashion. J Biol Chem 278: 10232-10238, 2003.

16. Moncada S, Palmer RM and Higgs EA: Nitric oxide: physiology, pathophysiology and pharmacology. Pharmacol Rev 43: 109-142, 1991.
17. Lamarque D and Whittle BJ: Role of oxygen-derived metabolites in the rat gastric mucosal injury induced by nitric oxide donors. Eur J Pharmacol 277: 187-194, 1995.

18. Freeman B: Free radical chemistry of nitric oxide. Looking at the dark side. Chest 105: 79S-84S, 1994.

19. Borutaite V and Brown GC: Nitric oxide induces apoptosis via hydrogen peroxide, but necrosis via energy and thiol depletion. Free Radic Biol Med 35: 1457-1468, 2003.

20. Liu Q, Chan ST and Mahendran R: Nitric oxide induces cyclooxygenase expression and inhibits cell growth in colon cancer cell lines. Carcinogenesis 24: 637-642, 2003.

21. Zeng H, Spencer NY and Hogg N: Metabolism of S-nitrosoglutathione by endothelial cells. Am J Physiol Heart Circ Physiol 281: H432-H439, 2001.

22. Liu W, Reinmuth N, Stoeltzing O, et al: Cyclooxygenase-2 is up-regulated by interleukin-1 beta in human colorectal cancer cells via multiple signaling pathways. Cancer Res 63: 36323636, 2003.

23. Tamura M, Sebastian S, Yang S, et al: Up-regulation of cyclooxygenase-2 expression and prostaglandin synthesis in endometrial stromal cells by malignant endometrial epithelial cells. A paracrine effect mediated by prostaglandin E2 and nuclear factor-kappa B. J Biol Chem 277: 26208-26216, 2002.

24. Inoue $\mathrm{H}$ and Tanabe $\mathrm{T}$ : Transcriptional role of the nuclear factor -kappa B site in the induction by lipopolysaccharide and suppression by dexamethasone of cyclooxygenase-2 in U937 cells. Biochem Biophys Res Commun 244: 143-148, 1998.

25. Surh YJ, Chun KS, Cha HH, Han SS, Keum YS, Park KK and Lee SS: Molecular mechanisms underlying chemopreventive activities of anti-inflammatory phytochemicals: downregulation of COX-2 and iNOS through suppression of NFkappa B activation. Mutat Res 480-481: 243-268, 2001.

26. Duque J, Diaz-Munoz MD, Fresno M and Iniguez MA: Upregulation of cyclooxygenase-2 by interleukin-1 beta in colon carcinoma cells. Cell Signal 18: 1262-1269, 2006.

27. Hansen WR, Marvin KW, Potter S and Mitchell MD: Tumor necrosis factor-alpha regulation of prostaglandin $\mathrm{H}$ synthase- 2 transcription is not through nuclear factor-kappa $\mathrm{B}$ in amnionderived AV-3 cells. Placenta 21: 789-798, 2000.

28. Gulati AP, Yang YM, Harter D, et al: Mutant human tumor suppressor p53 modulates the activation of mitogen-activated protein kinase and nuclear factor-kappa $\mathrm{B}$, but not c-Jun Nterminal kinase and activated protein-1. Mol Carcinog 45: 26-37, 2006.

29. Calmels S, Hainaut $\mathrm{P}$ and Ohshima $\mathrm{H}$ : Nitric oxide induces conformational and functional modifications of wild-type p53 tumor suppressor protein. Cancer Res 57: 3365-3369, 1997.

30. Benoit V, de Moraes E, Dar NA, et al: Transcriptional activation of cyclooxygenase- 2 by tumor suppressor p53 requires nuclear factor-kappa $\mathrm{B}$. Oncogene 25: 5708-5718, 2006.

31. Chen JJ, Huang WC and Chen CC: Transcriptional regulation of cyclooxygenase- 2 in response to proteasome inhibitors involves reactive oxygen species-mediated signaling pathway and recruitment of CCAAT/enhancer-binding protein delta and CREB-binding protein. Mol Biol Cell 16: 5579-5591, 2005.

32. Inoue H, Yokoyama $\mathrm{C}$, Hara $\mathrm{S}$, Tone $\mathrm{Y}$ and Tanabe T: Transcriptional regulation of human prostaglandin-endoperoxide synthase-2 gene by lipopolysaccharide and phorbol ester in vascular endothelial cells. Involvement of the nuclear factor for interleukin-6 expression site and cyclic-AMP response element. J Biol Chem 270: 24965-24971, 1995.

33. Tamura M, Sebastian S, Yang S, Gurates B, Fang Z, Okamura K and Bulun SE: Induction of cyclooxygenase- 2 in human endometrial stromal cells by malignant endometrial epithelial cells: evidence for the involvement of extracellularly-regulated kinases and CCAAT/enhancer-binding proteins. J Mol Endocrinol 31: 95-104, 2003. 